\title{
Measuring Meaningful Time Experiences in Intergenerational Relationships
}

\author{
Cheryl L. Peters, Cory R. Bolkan
}

\begin{abstract}
Time demands from competing obligations and responsibilities limit the amount of available time to spend in more meaningful activities, such as contact with family members. Because family time is compromised, adults experience feelings of guilt and regret over the lack of time spent with their aging and younger family members. Theoretical implications of how family time is experienced from multi-generational perspectives are missing in mainstream gerontological research. Qualitative research findings from a study of older adults (age range 67 to $86, M=76$ years) are connected to larger theoretical constructs in family gerontology. A tenitem measurement survey developed from the themes is proposed as an instrument for future research.
\end{abstract}

Key Words: Family gerontology, intergenerational ambivalence theory, qualitative method, measurement.

Cheryl Peters is the County Extension Director and Extension Educator for Presque Isle County, Michigan State University Extension, Rogers City, Michigan 49779. Electronic mail may be sent via the Internet to cpeters@msu.edu.

Cory Bolkam is Assistant Professor in the Department of Human Development, Washington State University, Vancouver, Washington 98686.

Contradictions often emerge between how adult family members would like to spend their time and how time in their daily lives is actually spent. Prior research indicates that individuals desire more quality time spent with loved ones, but that finding the time to do so in our fast-paced American society is challenging (Robinson \& Godbey, 1999). Time demands from external obligations (e.g., participation in paid labor) limit the amount of available time to spend in more meaningful activities, such as contact with older family members. Because family time is compromised, adults experience feelings of guilt and regret over the lack of time spent with their aging family members (Peters, Hooker, \& Zvonkovic, 2006). As a result, many try to manage the experience of guilt rather than make actual behavioral changes. Feelings of guilt and regret 
about how time is spent are further complicated when family members are elderly, ill, or die.

As families age, it may become more challenging to experience quality, meaningful time with each other (in light of competing life demands); however, it is the perception of quality of time spent together (rather than quantity of time or proximity) that more likely enhances wellbeing (Roberto, Allen, \& Blieszner, 1999). To date, there are no psychometrically sound measures that adequately capture the depth of meaningful time experiences between older parents and their family members.

A new measurement instrument was developed by examining the intergenerational ambivalence theoretical framework (Luescher \& Pillemer, 1998) and family gerontology literature related to emotional outcomes from interactions, studies of shared time, debating family time verses family leisure activities, and older parents' perceptions of time. The survey proposed is called Meaningful Time Experiences in Intergenerational Relationships. The ten items represent the four categories in the literature listed above. The purpose of this measure is to capture how older adults value shared time experiences with family. This measure would be particularly useful to integrate with other research surveys or along side qualitative interviews. Questions are based on micro events of interactions such as conversations, visits, exchanges of help, and memories of the past that are still relevant to the relationship in present time.

The survey is designed for asking about a family relationship with someone from a different generation, older than 18 years (adults). Other short introduction questions assess the respondent's family relationship type (e.g., biological, legal), parent or grandparent status, and age or cohort membership (Willson, Shuey, \& Elder, 2003). As an alternative of asking the respondents' age and the age of the corresponding family member, the age could be exchanged for year born for cohort analyses of family relationships. All ten survey items are presented with an example quote from an older parent who participated in the qualitative study that was the research source for the development and theoretic work behind this measure. The shortness of the scale is suitable for research with the older population and could even be asked verbally in future studies.

\section{Older Parent Study}

In the present study we conducted semi-structured interviews with older parents ( $M=76$ years) to examine the perspectives of mothers and fathers discussing relationship experiences with their adult children. Relationship dynamics and experiences with 75 adult children were the 
focus of the interviews, however, additional ties with grandchildren and in-laws were also discussed. Participants were interviewed in their homes, so field observations became an additional data source, particularly for the assessment of socio-economic status. The sample ranged with older parents from working class to upper-middle class backgrounds. Socioeconomic status depended on current household characteristics, occupational history, and lifestyle conditions including sources of income, levels of assistance, and ability to financially assist other people.

Qualitative analysis techniques guided the coding of interview transcripts to uncover themes. Eight themes emerged from the use of codes and memos during the data reduction and organizational phases of the analysis (boundaries and influence; time experiences; emotions and uncertainty; positive perceptions; health and aging concerns; gender differences; geographic distance; life phase and decision-making). For a summary of themes from the qualitative study, see: Peters, C. L., Hooker, K., \& Zvonkovic, A. M. (2006). Older parents' perceptions of ambivalence in relationships with their children. Family Relations, 55, (Special Issue on Family Gerontology), 539-551. The results from the older parent study created the foundation for the proposed measure.

\section{Proposed Ten-Item Measure}

\section{Meaningful Time Experiences in Intergenerational Relationships}

Think about a family relationship with someone from a different generation who is older than 18 years (an adult). You may think about your adult son or daughter, or adult grandchild. If you wish to consider a relationship by law or formed in marriage, please indicate that in the next series of questions.

What is your age?

What age is the person you are thinking about?

Please indicate the most appropriate relationship pair that describes who you are thinking about:

Parent - Child Grandparent - Grandchild Other:

Is this a biological or otherwise a family relationship? Yes No

Is this a relationship by law or marriage (in-law; step)? Yes No 
When reading the following statements, please score on the provided numbered scale the extent to which you agree that statement is true for your relationship, at this time.

Lower numbers indicate less agreement with the statement. Higher ratings mean stronger agreement that the statement reflects your current relationship.

\begin{tabular}{lrrrrrrrrr}
1 & 2 & 3 & 4 & 5 & 6 & 7 & 8 & 9 & 10 \\
No Agreement & & & & & Strongest Agreement \\
\hline
\end{tabular}

a. In your relationship, you believe you talk about things that are meaningful with each other.

b. After you visit or have a conversation with this family member, you have a feeling of closeness that lasts for a while.

c. On most occasions, you hide some feelings or opinions from this person.

d. Overall, you feel that you can "be yourself" when you speak or visit with this person.

e. When you spend time with this person, it often feels like leisure time. That is, you usually do not feel rushed and the time is enjoyable.

f. Sometimes when you share time with this person, some of the experience feels artificial or not genuine.

g. When this family member calls you or drops in for a visit "out of the blue", you feel thought about, valued, or appreciated.

h. Some of your most cherished time together involves "just being with each other" and "not having to do anything."

i. When you think about this relationship, you feel guilty or saddened about the lost time together.

j. You often wish for more time together with this person, but understand that life is busy and there are often many things to do everyday. 


\section{Theoretical Rationale and Research Support for Measurement with Examples of Older Parents' Perceptions}

The first two items of the measure focus on feelings of closeness. Benefits of positive interactions include the following: improved physical health, heightened self-esteem or feelings of self-worth, enhanced intellectual stimulation, and opportunities for self-fulfillment. There can be a positive influence of family interaction. Shared leisure can lead to improved communication, increased perceived quality in the relationship, and enhanced family cohesiveness (Gabriel \& Bowling, 2004; Orthner \& Mancini, 1990).

Item $A$

"Seeing that I talk to Anne more often, we have more of an overall knowing what's going on conversation." (Marie)

Item $B$

"I love to share in their experiences when I can, or just hear about them." (Judith)

The next two items of the measure target the genuineness of the experienced time together. When time spent together is believed to be real, it means the person feels there is a non-instrumentality of the pursuit or an intrinsic motivation for the shared time (Hebblethwaite \& Norris, 2006). Perceptions of freedom in shared real time means the person feels at ease to be himself or herself; he or she feels a level of sincerity in the interaction. Feelings of shared time are socially constructed. Hiding feelings or opinions may be related to the generational stake hypothesis. Older parents often highlight only positive features of their children and the experiences in their relationships. Older adults are careful to avoid situations that evoke differences or problems in the relationship (Pyke, 1999). An intergenerational ambivalence perspective reminds us that both positive and negative sentiment can occur simultaneously (Luescher \& Pillemer, 1998).

Additionally, socio-economic status may influence the experience of shared time between generations. As Lareau (2003) points out about class and family life in American society; White, upper-income families focus heavily on structured and paid-for activities for children and that can take precedence over just visiting and being with older, related kin. Class upbringings and current status likely influence the meanings of shared time in later life. The perception or reality of being crunched for time in daily lives, due to competing demands, can create different reactions from 
people due to their class membership and the values or traditions that are carried with class and upbringings.

Item $C$

"We don't intrude upon their thinking, their activities...(my wife) and I...very carefully avoid any comment, because the friendship relationship that exists between us is more important than having our own way. We would just rather back away...so we don't get into arguments or into disputes over our differences in ideas and feelings. (Henry)

Item D

"It kind of disgusts my wife sometimes, she'll say, 'well, what did you talk about?' and I'll say nothing. 'hand me that hammer, or I need some more nails.' To me, that is quality time. I think, all three of my sons respect that. Now my wife, if she was there, she would ask questions. (laughs) And I just don't." (Andy)

Four of the measure's items target the tempo and emotional tones of the time spent together. Family time is an idiosyncratic experience. Meanings of family time vary by family members, possibly between generations (Daly, 1996; 2001). Dereifying family time means there can be hidden dimensions in shared family time, silent languages that shade the experience (Shaw 1992). Family time is the source of memories of the relationship. Many times traditions are created and recreated in meaningful time experiences. Quantity of time is necessary to create opportunities for quality time - you have to have time together to make memories and quietly transmit values and traditions.

Family time is highly valued when it is seen as unscheduled or spontaneous (Daly, 2001). With an awareness of just being together, positive constructs of togetherness filter into memories of the person. Not enough calm, positive time together can evoke tension and conflict (Daly, 1996). Bloated schedules can lead to a sense of "busyness" and meaningful time together can feel elusive, even unachievable. The busyness of family interaction may be a result of crowded time - with increased access to technology, the lines dividing work, family time, and personal time are blurred and hurried (Daly, 1996). Shaw (1992) reminds us that we must communicate with each other in meaningful ways to stay connected. Finally, leisure is no longer conceptualized as a type of activity; it is more about the subjective meanings of how our time is spent in daily life (Shaw, 1992). 
Item $E$

"I think hanging out [is quality time] Taking walks and talking. Ya, I think environments for talking, and just being, not really doing anything." (Mark)

Item $F$

"We have had the experience that they haven't had. And sometimes we feel that they are not doing right sometimes with their children. But we don't say anything, that's their thing. If they ask for advice, we tell them. You just can't, as much as you'd like to, you just can't interfere." (Bob)

Item $G$

"Just the idea that they thought enough to call me up and talk $i s$ quality time together." (Helen)

Item $H$

"I think that if you can just be with them. Be relaxed...that to me is quality time." (Mick)

The last two items of the measure capture emotions and perceptions about time. Older parents' perspectives are important. Adult children's lives and the quality of relationship they have with their aging parents, shapes the identity of the parent and the social integration perceived by the older parent, in a way that is not the same for the adult child (Roberto et al., 1999). Additionally, a study of daily emotional experiences has shown that older adults were more likely than younger adults to report having mixed feelings and complex emotions-a feature referred to as "poignancy" in the literature (Carstensen, Pasupathi, Mayr, $\&$ Nesselroade, 2000, p. 653). Time spent with family members can cause people to feel multiple positive and negative emotions at the same time or over the same event. Older parents who feel strongly that relationships with their adult children are important to their personal identity, may likely experience ambivalence and emotional poignancy from shared time experiences (Peters et al., 2006).

An intergenerational ambivalence perspective reminds us that societal norms and role expectations of the parent-child relationship exist in our experience of the social world (Connidis \& McMullin, 2002). Without periodic negotiation, parent-child relations may become awkward, tenuous, or disconnected in late life. Relationships with others create ambivalent experiences for individuals. Social or structural 
conditions, such as employment status or busyness, can place constraints on how individuals may act with agency, or otherwise do what they wish without considering others' reactions (Connidis, 2001).

Item $I$

"I wouldn't say that I spent a great deal of time with my kids. My wife can tell me, 'do you remember when this happened or remember when that happened?' and I say, all I was thinking about was my job. I can't remember." (Bill)

"I regret that I didn't get to spend as much time as I wanted to with my kids." (John)

Item $J$

"I'd love to have even the local ones visit more...oh, I understand, certainly I do, and I can't be selfish. After all, they all have their own lives." (Henry)

"I'm so proud of my children...I've been very fortunate. The only thing I might say is, I worry that they work too hard. It's just very busy times. I think that we live such a fast life now." (Jean)

The mixed emotions and perceptions of busyness may stem from an over-reliance on self-independence. The older adults participating in the present study were all in general good health and were living on their own in the community. It seems that a sample of older adults with more health problems, or who were receiving more care or assistance with their daily living, would have additional complexities to their situations. Likewise, conditions of troubled times, such as during challenging economic downturns, and with inevitable family tragedies such as severe illness and death, may complicate family relations. This instrument was developed as a baseline of average interactions among generations. The items can be compared with other psychological and social measurements to understand how social norms and institutions impact families.

\section{Conclusion}

Themes from the older parents' reports, as well as theoretical rationale and supporting research, provided the foundation of the Meaningful Time Experiences in Intergenerational Relationships measure. The development of the proposed measure combines the multiple meanings of shared time experiences from the perspective of one older individual considering a number of dyadic relationships (with sons, daughters, in-laws). Survey items are connected to theoretical concepts 
from family gerontological literature. The scale is ready for testing and integration into larger studies on late life family relationships. Future research designs that include perceptions of how time is spent, the meaning of time shared with aging or ill family members, as well as connections to both individual psychological well-being and family relationships are possible. Future research can help clarify the causes and contexts of these responses about meaningful time experiences from older parents in American society. 


\section{References}

Carstensen, L., Pasupathi, M., Mayr, U., \& Nesselroade, J. R. (2000). Emotional experiences in everyday life across the adult life span. Journal of Personality and Social Psychology, 79, 644-655.

Connidis, I. A. (2001). Family ties and aging. Thousand Oaks, CA: Sage.

Connidis, I. A., \& McMullin, J. (2002). Ambivalence, family ties, and doing sociology. Journal of marriage and Family, 64, 594-601.

Daly, K. J. (1996). Families and Time: Keeping pace in a hurried culture. Sage: Thousand Oaks.

Daly, K. J. (2001). Deconstructing family time: From ideology to lived experience. Journal of Marriage and Family, 63, 283-294.

Gabriel, Z., \& Bowling, A. (2004). Quality of life from the perspective of older people. Aging and Society, 24, 675-691.

Hebblethwaite, S., \& Norris, J. E. (2006). The family that plays together, stays together? Using ambivalence to theorize about intergenerational family leisure. Working paper presented at the annual meeting of the National Council on Family Relations, Minneapolis, MN.

Lareau, A. (2003). Unequal childhoods: Class, race, and family life. University of California Press: Berkeley, CA.

Luescher, K., \& Pillemer, K. (1998). Intergenerational ambivalence: A new approach to the study of parent-child relations in later life. Journal of Marriage and the Family, 60, 413-425.

Orthner, D. K., \& Mancini, J. A. (1990). Leisure impacts on family interaction and cohesion. Journal of Leisure Research, 22, 125137.

Peters, C. L., Hooker, K., \& Zvonkovic, A. M. (2006). Older parents' perceptions of ambivalence in relationships with their children. Family Relations, 55, (Special Issue on Family Gerontology), 539551.

Pyke, K. (1999). The micropolitics of care in relationships between aging parents and adult children: Individualism, collectivism, and power. Journal of Marriage and the Family, 61, 661-672. 
Roberto, K., Allen, K., \& Blieszner, R. (1999). Older women, their children, and grandchildren: A feminist perspective on family relationships. Journal of Women \& Aging, 11, 67-84.

Robinson, J., \& Godbey, G. (1999). Time for life: The surprising ways Americans use their time. Pennsylvania State University Press: College Park, PA.

Shaw, S. M. (1992). Derifying family leisure: An examination of women's and men's everyday experiences and perceptions of family time. Leisure Sciences, 14, 271-286.

Willson, A., Shuey, K., \& Elder, G. (2003). Ambivalence in the relationship of adult children to aging parents and in-laws. Journal of Marriage and Family, 65, 1055-1072. 